\title{
A single-center United States experience with bleeding Dieulafoy lesions of the small bowel: diagnosis and treatment with single-balloon enteroscopy
}

Authors

Institutions
Seth Lipka', Roshanak Rabbanifard ${ }^{2}$, Ambuj Kumar ${ }^{3}$, Patrick Brady ${ }^{2}$

Institutions are listed at the end of article. accepted after revision 23. February 2015

\section{Bibliography}

Dol http://dx.doi.org/ 10.1055/s-0034-1391901

Published online: 24.6 .2015 Endosc Int Open 2015; 03: E339-E345

(c) Georg Thieme Verlag KG Stuttgart · New York E-ISSN 2196-9736

\section{Corresponding author} Seth Lipka, M.D.

12901 Bruce B. Downs Blvd. MDC 72

Tampa, Florida 33612 United States

Fax: (813) 805-9863

slipka@health.usf.edu submitted 22. May 2014

Introduction: A Dieulafoy lesion (DL) of the small bowel can cause severe gastrointestinal bleeding, and presents a difficult clinical setting for endoscopists. Limited data exists on the therapeutic yield of treating DLs of the small bowel using single-balloon enteroscopy (SBE).

Methods: Data were collected from Tampa General Hospital a 1 018-bed teaching hospital affiliated with University of South Florida in Tampa, Florida. Patients were selected from a database of patients that underwent SBE from January 2010 August 2013.

Results: Eight patients were found to have DL an incidence of $2.6 \%$ of 309 SBE performed for obscure gastrointestinal bleeding. 7/8 were identified in the jejunum, with one found in the duodenum. The mean age of patients with DL was 71.5

\begin{tabular}{llll}
\hline \multicolumn{2}{l}{ Abbreviations } & MI & myocardial infarction \\
$\nabla$ & & MR & mitral regurgitation \\
A & anterograde & N/A & data not available or missing \\
Afib & atrial fibrillation & N/P & not performed \\
APC & argon plasma coagulation & OGIB & obscure gastrointestinal bleeding \\
AS & aortic stenosis & OSA & obstructive sleep apnea \\
ASA & aspirin & PPI & proton pump inhibitor \\
AVM & arteriovenous malformation & PPM & permanent pacemaker \\
AVR & aortic valve replacement & PUD & peptic ulcer disease \\
BAE & balloon assisted enteroscopy & SBCE & wireless small-bowel capsule endoscopy \\
C & colonoscopy & SBE & single-balloon enteroscopy \\
CABG & coronary artery bypass graft & TR & tricuspid regurgitation \\
CHF & congestive heart failure & W & white
\end{tabular}

COPD chronic obstructive pulmonary disease

CVA cerebral vascular accident

DBE double-balloon enteroscopy

DL Dieulafoy lesion

DM diabetes mellitus

EGD esophagogastroduodenoscopy

Epi epinephrine injection

GERD gastroesophageal reflux disease

HLD hyperlipidemia

License terms

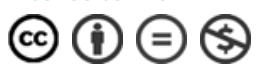

HTN

IR hypertension

interventional radiology embolization years old. $6 / 8$ patients were on some form of anticoagulant/antiplatelet agent. The primary modality of therapy employed was electrocautery, multipolar electrocoagulation in seven patients and APC (argon plasma coagulation) in one patient. In three patients, electrocoagulation was unsuccessful and hemostasis was achieved with clip placement. Three patients required repeat SBE with one found to have rebleeding from a failed clip with hemostasis achieved upon reapplication of one clip.

Conclusion: In our United States' experience, SBE offers a reasonable therapeutic approach to treat DL of the small bowel with low rates of rebleeding, no adverse events, and no patient requiring surgery.

\section{Introduction \\ $\nabla$}

Secondary to the lack of clear pathology evident until after surgery or autopsy, the small bowel has been considered the "black box" of the gastrointestinal tract. In the 1980's push enteroscopy was developed allowing examination and endoscopic therapy of the proximal jejunum [1]. In 2001 the small bowel capsule endoscopy (SBCE) 
finally made identification of the culprit lesion, responsible for chronic or acute bleeding in the small bowel, possible in a less invasive manner [2]. Unfortunately SBCE is only diagnostic and does not allow biopsies or treatment. Balloon assisted enteroscopy (BAE) using either a single or double-balloon technique opened the door for possible visualization of the entire small bowel tract with the ability to treat or biopsy previously unreachable areas. When both anterograde and retrograde routes are used successively, a "total" enteroscopy has been reported in up to $86 \%$ of patients [3]. However, more modest rates have been reported in three randomized controlled trials where complete enteroscopies reportedly ranged from $0 \%$ to $22 \%$ in SBE and $18.5 \%$ to $66 \%$ in DBE (RR, $1.73 ; 95 \% \mathrm{CI}, 0.86-3.48 ; P=0.12$ ) [ $4-6]$.

Dieulafoy lesion (DL) is a recognized cause of gastrointestinal bleeding since the first reported case in the late $1800 \mathrm{~s}$ [7]. It accounts for up to $5 \%$ of all instances of acute upper gastrointestinal bleeds [8]. DLs are found throughout the gastrointestinal tract, but are usually located in the proximal stomach along the lesser curvature. Rarely, these lesions may be found in the small bowel and present an anatomical dilemma secondary to the inability to reach these lesions by esophagogastroduodenoscopy (EGD) or colonoscopy for endoscopic treatment. Previously, small-bowel DL were identified via angiography and treated with either conservative management or surgical resection in cases of massive hemorrhage [9]. However, since the initial case report in 1990 by Goldenberg et al. describing the endoscopic characteristics and management of small bowel DL, questions regarding a feasible alternative to surgical therapy have surfaced [10]. Limited data exists regarding enteroscopic treatment for these lesions with only one Austrian experience where ten cases were treated with either a single or double-balloon enteroscopy [11]. In this report we have reviewed our SBE data base to determine the outcomes for patients that were treated for bleeding small-bowel DL since 2010.

\section{Methods}

$\nabla$

Institutional Review Board approval was obtained from the University of South Florida and Tampa General Hospital. Patients were selected from a database of patients that underwent SBE from January 2010-August 2013at Tampa General Hospital. Over this time 375 SBEs were performed for patients with suspected or documented small bowel bleeding unreachable with either EGD or colonoscopic modalities. A total of 309 patients underwent SBE with 348 performed anterograde, and 27 retrograde. Forty-two patients required more than one SBE, either bidirectional or repeated in the same direction.

We collected information on demographics including: age, sex, comorbidities, smoking, alcohol, and use of anticoagulation/antiplatelet agents or proton pump inhibitor therapy. The diagnostic techniques used before SBE were also recorded including EGD, colonoscopy, push enteroscopy, SBCE, and angiography. The hemodynamic status of each patient was characterized by recording initial heart rate, blood pressure, hemoglobin, and number of units of packed red blood cells transfused over the course of treatment $(\bullet$ Table $\mathbf{1})$.

\section{Treatment}

Diagnosis of DL was based on the finding of one of the three following criteria [11]:
1. A spurting artery or micropulsatile artery streaming from either a small mucosal defect or normal surrounding mucosa;

2. Appearance of a fresh, adherent clot with a narrow point of attachment either to a small mucosal defect or to normal surrounding mucosa; or

3. Visualization of a protruding vessel with or without active bleeding within either a small mucosal defect or within normal mucosa.

The choice of hemostasis was left to the preference of the endoscopist. In our population: Either multipolar Gold probe (Boston Scientific, Natick, Massachusetts, United States) or argon plasma coagulation (Erbe Elektromedizin, Tübingen, Germany) was the primary therapeutic modality. When these modalities failed a hemoclip application (Resolution Clip; Boston Scientific, Natick, Massachusetts, United States) was performed.

Data were retrieved from a review of hospital medical records and by contacting patients via telephone. Follow-up was defined as the time between enteroscopic hemostasis and last patient contact, first rebleeding episode, or death.

\section{Evaluation}

Initial evaluation of all our patients for suspected obscure gastrointestinal bleeding (OGIB) included both an initial EGD and colonoscopy as per current expert panel recommendations [12]. OGIB is defined as "occult or overt bleeding that persists or recurs after an initial negative endoscopic evaluation including colonoscopy and EGD". Occult OGIB refers to iron deficiency anemia or a positive fecal occult blood test when there is no evidence of visible blood, whereas overt bleeding is categorized as bleeding from the gastrointestinal tract that persist or recurs without an obvious etiology after EGD or colonoscopy.

SBCE was performed to assess the location of the lesion. Patients with a history of inflammatory bowel disease or potential causes of small bowel obstruction were evaluated with a patency capsule study before SBCE. The initial approach to SBE was determined based on the combination of clinical symptoms (i.e. melena vs hematochezia), and results of the SBCE where lesions found in the first $75 \%$ of the small bowel were approached anterograde. A retrograde approach was used in cases where lesions were suspected in the distal $25 \%$. If no bleeding was detected on initial enteroscopy, a submucosal tattoo was placed to mark the deepest insertion point, and the other enteroscopic route was performed. In cases where bleeding continued, but no lesion was detected on SBCE, an anterograde approach was used as the initial method of choice. Entire small bowel enteroscopy was not performed if the suspected primary lesion was found and hemostasis was achieved on the initial enteroscopic approach. In cases where rebleeding was suspected, the initial diagnostic approach was repeated so repeat endoscopic therapy could be performed when necessary. Interventional radiological embolization or surgical intervention was planned only when endoscopic hemostasis could not be achieved.

\section{Single-balloon enteroscopy}

Single-balloon enteroscopy (SBE) systems consists of a high-resolution endoscope (SIF-Q180; Olympus Medical, Center Valley, Pennsylvania, United States) with a working length of $200 \mathrm{~cm}$, $9.2 \mathrm{~mm}$ in diameter, and contains a working channel of $2.8 \mathrm{~mm}$ diameter. The disposable overtube (ST-SB1; Olympus Medical) was $140 \mathrm{~cm}$ long with a $13.2 \mathrm{~mm}$ outer diameter, and was equipped with a latex-free balloon at the tip where air can be inflated and deflated from a pressure-controlled pump system allowing 
Table 1 Patient hemodynamic profiles.

\begin{tabular}{|c|c|c|c|c|c|c|}
\hline Patient & Clinical presentation & Occult/Overt & Hemoglobin (g/dL) & Pressors & Transfusion (units) & Hospitalization (days) \\
\hline 1 & Melena & Overt & 7.4 & No & 14 & 27 \\
\hline 2 & Melena & Overt & $\mathrm{N} / \mathrm{A}$ & No & N/A & 2 \\
\hline 3 & Melena & Overt & 5.5 & No & 7 & 6 \\
\hline 4 & Melena & Overt & 6.0 & No & 10 & 7 \\
\hline 5 & Melena & Overt & 9.3 & No & 7 & 6 \\
\hline 6 & Melena & Overt & 7.0 & No & 1 & 7 \\
\hline 7 & Melena & Overt & 8.7 & No & 3 & 3 \\
\hline 8 & Melena & Overt & 5.3 & No & 4 & 4 \\
\hline
\end{tabular}

\begin{tabular}{|c|c|c|c|c|c|c|c|c|}
\hline Case & Age (years) & Sex & Race & Comorbidities & Anticoagulant/Platelets & PPI & Smoking & Alcohol \\
\hline 1 & 86 & Men & W & $\begin{array}{l}\text { CABG, HTN, Afib with PPM, Bladder } \\
\text { Cancer, Gastritis }\end{array}$ & ASA, Coumadin & Yes & Yes & No \\
\hline 2 & 73 & Women & W & N/A & $\mathrm{N} / \mathrm{A}$ & N/A & N/A & N/A \\
\hline 3 & 63 & Men & W & $\begin{array}{l}\text { MI, CABG, CHF, Afib, HTN, AS, CVA, } \\
\text { OSA }\end{array}$ & ASA, Plavix & Yes & No & Yes \\
\hline 4 & 81 & Men & W & CABG, CHF, PPM, Afib, HTN, AVR & ASA, Plavix & No & No & Yes \\
\hline 5 & 69 & Women & W & $\begin{array}{l}\text { GERD, PUD (non-bleeding), duode- } \\
\text { nal stenosis, benign colon polyps }\end{array}$ & ASA & Yes & Yes & No \\
\hline 6 & 60 & Women & W & PUD, anemia, COPD & None & Yes & Yes & No \\
\hline 7 & 60 & Women & Other (Trinidad) & MI, CHF, HTN, HLD, DM, Anemia & ASA & No & No & No \\
\hline 8 & 80 & Men & W & MI, CHF, AS, MR/ TR, Afib, HTN, CVA & ASA, Plavix & No & Yes & No \\
\hline
\end{tabular}

Abbreviations: W, white; CABG, coronary artery bypass graft; HTN, hypertension; Afib, atrial fibrillation; PPM, permanent pacemaker; ASA, aspirin; MI, myocardial infarction; CHF, congestive heart failure; AS, aortic stenosis; CVA, cerebral vascular accident; OSA, obstructive sleep apnea; AVR, aortic valve replacement; GERD, gastroesophageal reflux disease; PUD, peptic ulcer disease; COPD, chronic obstructive pulmonary disease; HLD, hyperlipidemia; DM, diabetes mellitus; MR, mitral regurgitation; TR, tricuspid regurgitation; N/A, not available; PPI, proton pump inhibitor.

for passage through the small bowel [13]. For the anterograde approach, only an overnight fast was used, whereas bowel preparation was used in cases of retrograde SBE. SBE was performed by one of four experienced endoscopists. All eight cases where DL was identified were treated by a single endoscopist. Sedation with propofol was used for all patients.

\section{Statistical analysis}

Descriptive statistics were employed to summarize the demographic data. The success rate associated with use of SBE for bleeding DL was measured as the primary outcome. Duration of follow-up was expressed as the mean follow-up time.

\section{Results}

Small bowel DLs were found in eight patients during the study period. Small bowel DLs were found in an elderly population with an overall mean age of 71.5 years. One-half of the patients were male and the predominant race was white ( $7 / 8$ patients). Most patients were on either anticoagulation or antiplatelet therapy with four patients on at least two anticoagulant/antiplatelet agents (one was on both aspirin and Coumadin, three on aspirin/ Plavix), and 6/8 were on at least aspirin. Smoking was prevalent in half, and alcohol use was listed in $2 / 8$, however no patients used these agents together. A history of peptic ulcer disease (PUD) or GERD was listed in 3/8 patients. PPI therapy was used in four of the eight patients including two of the four who were on at least two anticoagulant/antiplatelet agents together ( $\bullet$ Table2).
All patients experienced overt OGIB and reported melena on initial examination. All patients underwent EGD, colonoscopy, and SBCE before SBE. One patient had push enteroscopy before SBE and another had a prior angiogram with failed arterial embolization. The mean time from the onset of symptoms until performance of SBCE was 60.6 days (range, 4-150; median, 30) and the mean time between SBCE and the diagnostic/therapeutic SBE was 75.9 days (range, 12-210; median, 30). In all cases, the SBCE was performed before the referral for SBE. There were no reports of angioectasia in any of the SBCE studies. The initial mean hemoglobin found in the DL population was $7.0 \mathrm{gm} / \mathrm{dL}$ (range, 9.3-5.3). All patients required packed red blood cell transfusions with the average use of 6.6 units (range, 3-14) required during hospitalization. All patients that were found to have DL underwent anterograde SBE with 7/8 lesions found in the jejunum and one found in the fourth portion of the duodenum. Active bleeding was observed in $6 / 8$ patients; two of the patients demonstrate oozing on initial diagnostic SBE ( $\bullet$ Table 2 and $\odot$ Table 3).

The primary modality of therapy employed was electrocautery, multipolar electrocoagulation in seven patients and APC in one ( Fig. 1 a, 1 b and $\odot$ Fig.2a,2b). Epinephrine injection was used as an adjuvant therapy to initially slow bleeding in two patients. In three patients, electrocoagulation was unsuccessful and hemostasis was achieved with clip placement (resolution clips) ( Video 1 and Video 2 ). The average hospitalization for overt OGIB secondary to DL was 7.8 days (range, 2-27). The mean follow-up time for patients diagnosed with DL was 17.5 months (range, 1.5-44). Three patients required repeat SBE with one found to have rebleeding from a failed clip. Two patients requiring repeat SBE were treated initially with bipolar/clip (one pa- 


Orignal a ticle

\begin{tabular}{|c|c|c|c|c|c|c|c|c|c|}
\hline $\begin{array}{l}\text { Pa- } \\
\text { tient }\end{array}$ & $\begin{array}{l}\text { Diagnostic } \\
\text { modality }\end{array}$ & Location & $\begin{array}{l}\text { DBE } / \\
\text { SBE }\end{array}$ & Approach & $\begin{array}{l}\text { Enteroscopy } \\
\text { (\#) }\end{array}$ & Treatment (\#) & Finding & $\begin{array}{l}\text { AVM anywhere } \\
\text { in gastrointesti- } \\
\text { nal tract }\end{array}$ & $\begin{array}{l}\text { Re- } \\
\text { bleed }\end{array}$ \\
\hline 1 & $\mathrm{E} / \mathrm{C} / \mathrm{SBCE} / \mathrm{IR}$ & Jejunum & SBE & A & 2 & Bipolar/APC/Clip (1) & Active bleeding & No & No \\
\hline 2 & $E / C / S B C E$ & Jejunum & SBE & A & 1 & Bipolar & Spurting & No & No \\
\hline 3 & $\mathrm{E} / \mathrm{C} / \mathrm{SBCE}$ & Jejunum & SBE & A & 2 & Bipolar/ Epi/ Clip (2) & Active bleeding & No & No \\
\hline 4 & $\mathrm{E} / \mathrm{C} / \mathrm{SBCE}$ & Jejunum & SBE & A & 1 & Bipolar & Active bleeding & No & No \\
\hline 5 & $\mathrm{E} / \mathrm{C} / \mathrm{SBCE}$ & $\begin{array}{l}4^{\text {th }} \text { portion } \\
\text { duodenum }\end{array}$ & SBE & A & 3 & Bipolar/ Clip (1) & Oozing & No & No \\
\hline 6 & $\begin{array}{l}\text { E/C/ SBCE/ push } \\
\text { enteroscopy }\end{array}$ & Jejunum & SBE & A & 2 & Bipolar/ Clip (4) & Oozing & No & Yes \\
\hline 7 & $\mathrm{E} / \mathrm{C} / \mathrm{SBCE}$ & Jejunum & SBE & A & 1 & APC & Active bleeding & No & No \\
\hline 8 & $\mathrm{E} / \mathrm{C} / \mathrm{SBCE}$ & Jejunum & SBE & A & 2 & Epi/Bipolar & Active bleeding & No & No \\
\hline
\end{tabular}

Abbreviations: DBE, double-balloon enteroscopy; SBE, single-balloon enteroscopy; AVM, arteriovenous malformation; E, esophagogastroduodenoscopy; C, colonoscopy; SBCE, wireless small-bowel capsule endoscopy; IR, interventional radiology embolization; A, anterograde; APC, argon plasma coagulation; Epi, epinephrine injection.
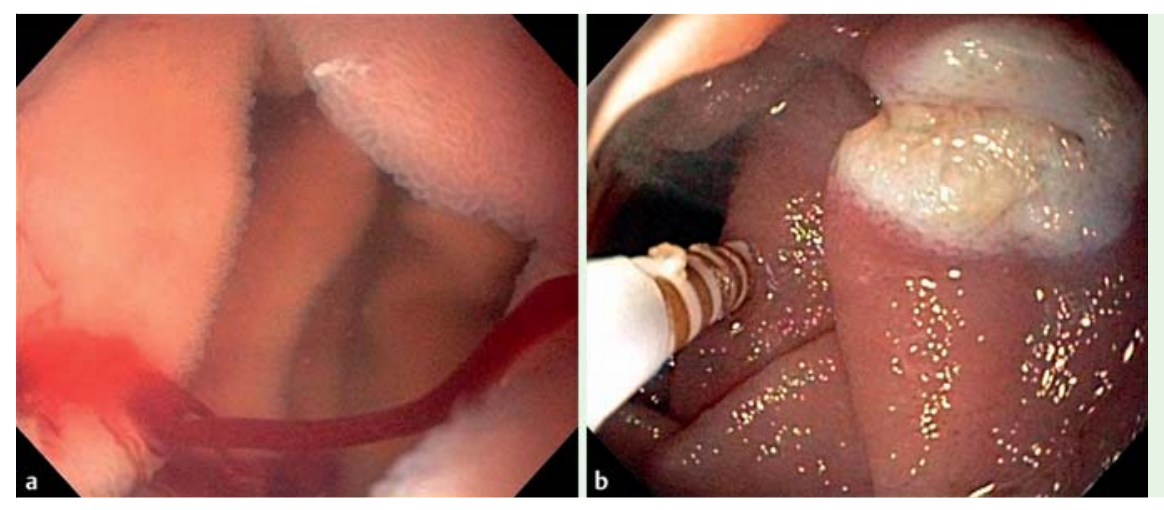

Fig. 1 a Active bleeding from mid jejunal Dieulafoy lesion. $\mathbf{b}$ Cessation of bleeding post therapy.
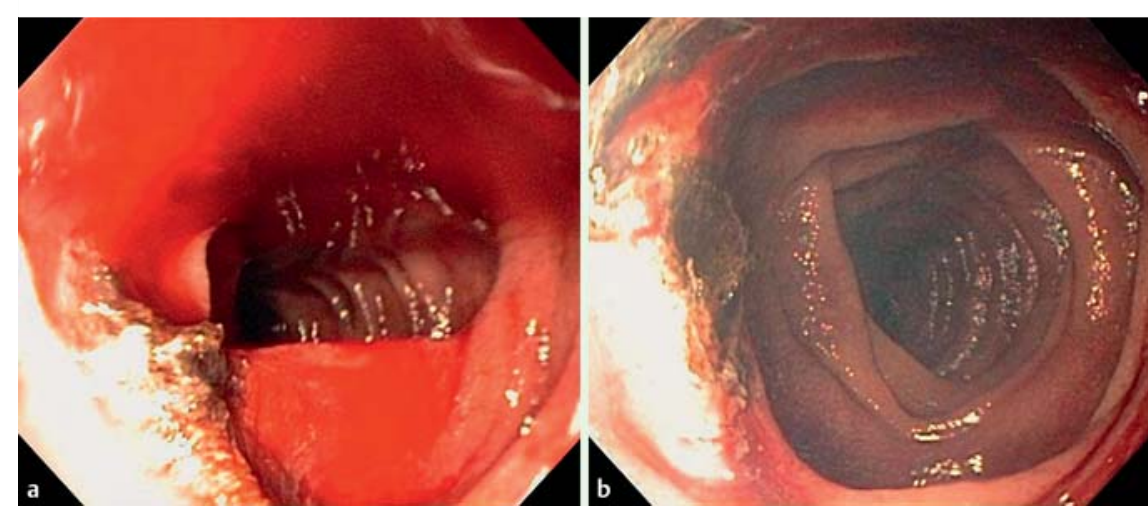

Fig2 a Active bleeding from jejunal Dieulafoy lesion after initial argon plasma coagulation. b Cessation of bleeding after final argon plasma coagulation therapy.

tient treated with four clips and the second with one clip), and the third patient initially treated with epinephrine/bipolar therapy. The patient treated with four clips was found to have rebleeding occurring two weeks after the initial SBE and achieved hemostasis with reapplication of one clip. Repeat SBE was performed at two months and four months in patient five, however

\section{Video 1}

Dieulafoy lesion (DL) identified during single-balloon enteroscopy in the mid jejunum. Initially, the lesion was actively bleeding with a steady stream of blood in the absence of an identifiable mucosal ulceration or angioectasia. After identification, the lesion was treated successfully using multipolar electrocauterization.

online content including video sequences viewable at: www.thieme-connect.de no rebleeding was noted at the tattooed area where the previous DL was identified. Patient number 8 had noted rebleeding 44 months post initial anterograde SBE; a subsequent anterograde SBE was negative for bleeding, and bleeding resolved with conservative management ( $\bullet$ Table 3 and $\bullet$ Table 4 ).

\section{Video 2}

Dieulafoy lesion (DL) identified during single-balloon enteroscopy in the jejunum. Initially, the lesion was oozing with an adherent clot. After initial treatment with argon plasma coagulation therapy the lesion began to bleed actively, but with further treatment bleeding ceased.

online content including video sequences viewable at:

www.thieme-connect.de 


\begin{tabular}{|llll|}
\hline Patient & Repeat enteroscopy/rebleed & Time to rebleed (days) & Time since last treatment (months) \\
\hline 1 & No repeat & - & 12 \\
\hline 2 & No repeat & - & 19 \\
\hline 3 & No repeat & - & 18 \\
\hline 4 & No repeat & - & 8 \\
\hline 5 & $\begin{array}{l}2 \text { months \& 4 months (No active bleed- } \\
\text { ing found at tattooed area) }\end{array}$ & - & 7 \\
\hline 6 & Repeat (Failed clip, re-applied) & 12 & $46^{*}$ \\
\hline 7 & No repeat & - & 15 \\
\hline 8 & 44 months (No active bleeding found) & - & 44 \\
\hline
\end{tabular}

Table 4 Patient follow-up information.

Note: *, days

Table 5 Incidence of small-bowel Dieulafoy lesion and obscure gastrointestinal bleeding.

\begin{tabular}{|c|c|c|c|c|c|c|c|c|c|c|c|c|}
\hline Study & $\begin{array}{l}\text { DL } \\
\text { (\#) }\end{array}$ & $\begin{array}{l}\text { Capsule } \\
\text { positive }\end{array}$ & $\begin{array}{l}\text { Inci- } \\
\text { dence } \\
(\%)\end{array}$ & $\begin{array}{l}\text { Antero- } \\
\text { grade }\end{array}$ & $\begin{array}{l}\text { Duode- } \\
\text { num (\#) }\end{array}$ & $\begin{array}{l}\text { Jejunum } \\
\text { (\#) }\end{array}$ & $\begin{array}{l}\text { lleum } \\
\text { (\#) }\end{array}$ & $\begin{array}{l}\text { SBE } \\
(\#)\end{array}$ & $\begin{array}{l}\text { DBE } \\
\text { (\#) }\end{array}$ & $\begin{array}{l}>2 \text { enteroscopy } \\
\text { sessions before } \\
\text { diagnosis }\end{array}$ & $\begin{array}{l}\text { Re- } \\
\text { bleeds } \\
\text { (\#) }\end{array}$ & $\begin{array}{l}\text { Follow-up } \\
\text { (months) }\end{array}$ \\
\hline $\begin{array}{l}\text { Dulic-Lakovic } \\
\text { et al, } 2011 \\
\text { [11] }\end{array}$ & 10 & $\mathrm{~N} / \mathrm{A}$ & 3.5 & $9 / 10$ & 0 & 9 & 1 & 3 & 7 & 4 & $\begin{array}{l}2 \mathrm{DBE} \\
1 \mathrm{SBE}\end{array}$ & $\begin{array}{l}\text { Median, } \\
14.5\end{array}$ \\
\hline $\begin{array}{l}\text { Landaeta, et } \\
\text { al, } 2013 \text { [22] }\end{array}$ & 17 & $\mathrm{~N} / \mathrm{A}$ & 7.2 & $12 / 17$ & $\mathrm{~N} / \mathrm{A}$ & $\mathrm{N} / \mathrm{A}$ & $\mathrm{N} / \mathrm{a}$ & $\mathrm{N} / \mathrm{A}$ & $\mathrm{N} / \mathrm{A}$ & 4 & 1 & Median, 9 \\
\hline $\begin{array}{l}\text { Chen et al, } \\
2010[23]\end{array}$ & 4 & $\mathrm{~N} / \mathrm{A}$ & 2.6 & $4 / 4$ & 0 & 4 & 0 & 0 & 4 & 0 & 1 & Mean, 8.8 \\
\hline $\begin{array}{l}\text { Prachayakul et } \\
\text { al, } 2013 \text { [24] }\end{array}$ & 5 & $\mathrm{~N} / \mathrm{A}$ & 4.31 & $5 / 5$ & 0 & 5 & 0 & 5 & 0 & $\mathrm{~N} / \mathrm{A}$ & 0 & $\mathrm{~N} / \mathrm{A}$ \\
\hline $\begin{array}{l}\text { Paliwal et al, } \\
2011[25]\end{array}$ & 5 & $3 / 4$ & N/A & N/A & 0 & 4 & 1 & 5 & 0 & 0 & 1 & $4-12$ \\
\hline
\end{tabular}

Abbreviations: DL, Dieulafoy lesion; N/A, data not available or missing; N/P, not performed; DBE, double-balloon enteroscopy; SBE, single-balloon enteroscopy.

\section{Discussion}

\section{$\nabla$}

DL lesions are now a well-recognized etiology of upper gastrointestinal bleeding with frequencies ranging from $0.5 \%$ to $14 \%$ [14-17]. DL may be found throughout the gastrointestinal tract from esophagus to the colon [9, 18,19], however, their distribution is uneven. Most occur in the stomach with (61\% to $82 \%)$ found in the proximal one-third, and up to $98 \%$ found in the upper stomach, predominantly on the lesser curvature $[20,21]$. Small-bowel DL first appeared in the literature in 1978 with two patients treated surgically for jejunal lesions [9]. However, cases with similar histology reported as "aneurysms" of the small bowel have been reported since 1944 [7]. In one systematic review, the mean percentage of DL located in the small bowel was $16 \%$ (duodenum, 15\%; jejunum-ileum, 1\%). The incidence of smallbowel DL as a cause of OGIB is sparsely reported ( $\bullet$ Table 5 ) [11, 22 - 26]. In patients undergoing BAE, the incidence of small-bowel DL is reported to range from $2.6 \%$ to $7.2 \%$ [11,22-24]. Our incidence of $2.6 \%$ is similar to the current literature, however, these may be vast underestimates as misidentified, non-bleeding DL, or those not reachable with BAE may lead to an underdiagnoses. The small mucosal defect often present and intermittent bleeding nature found in some DL may also contribute to underdiagnoses, or explain at least a portion of idiopathic cases of OGIB after negative BAE. One retrospective review of patients undergoing evaluation for OGIB found an incidence of $1.32 \%$ (3/227) small-bowel DL in patients undergoing SBCE that were later diagnosed on BAE [27]. Similar to our experience, the predominant location of small-bowel DL in several case series or retrospective reviews with BAE appears to be the jejunum (range $80 \%$ to $100 \%$ ) [11, $23-25]$.
Endoscopic management for general DL includes: banding, clipping, electrocautery, cyanoacrylate glue, sclerosant injection, epinephrine injection, heater probe, and laser therapy [28]. Epinephrine injection monotherapy is associated with higher rates of recurrent rebleeding [16], but may be useful in combination to slow bleeding and optimize visualization of the lumen for thermal/mechanical therapy. Studies have shown that mechanical endoscopic methods such as hemoclip and band ligation are more effective than injection and thermal therapy for general DL located predominantly in the stomach [29-33]. The optimal treatment approach for small-bowel DL has not been reported in any large scale study. Based on our experience, mechanical clipping may be the therapy of choice since it was successful in three cases where thermal methods failed, and in patient one where a prior interventional radiological embolization failed to stop bleeding.

Bleeding from small-bowel DL may be life threatening [34,35], and before 1990 was treated surgically. Goldenberg first reported a case of bleeding duodenal DL successfully treated with epinephrine injection therapy and electrocoagulation [10]. Sporadic case reports and case series have since surfaced reporting success with BAE $[11,22-26]$. In our population, either bipolar or APC therapy was used as initial therapy of choice. When these modalities failed a hemoclip was placed. This approach provided initial hemostasis in all eight patients. Initial hemostasis without rebleeding was $87.5 \%$ (7/8) in our series using SBE as our primary therapeutic modality and eventually reached $100 \%$ without any patients proceeding to surgery. Dulic-Lakovic et al reported rebleeding in 3/10 patients undergoing BAE (2/7 DBE, 1/3 SBE) with $2 / 10$ patients eventually requiring surgical intervention [11]. 
Chronic intermittent bleeding maybe encountered when treating small-bowel DL resulting in multiple BAEs before diagnosis. Dulic-Lakovic et al. reported 4/10 requiring at least two or more BAEs before diagnosis [11]. The diagnostic yield in patients undergoing first look endoscopy varies in gastric DL with reports ranging from $63 \%$ to $92 \%[2,36,37]$. From our experience with small-bowel DL all patients were diagnosed on initial SBE. The usefulness of repeating BAE after an initial negative BAE should be determined based on index of suspicion, previous diagnostic testing results, and the hemodynamic profile of each individualized patient.

The profile of our patients diagnosed with small-bowel DL included a group that was predominantly elderly (mean age, 71.5 years), and had multiple cardiac comorbidities 5/8 (62.5\%). A few case series of small-bowel DL treated with BAE reported a similar experience where mean ages of 69.7 and 77 years were reported although data on cardiovascular risk factors and anticoagulation/antiplatelet/NSAID use were unavailable $[11,23,38]$. Small-bowel DL does exist in younger patients. A study of $17 \mathrm{pa}-$ tients, median age 54 years (range, 15-80), reported a 15 year old treated for a small-bowel DL [22]. Cardiac comorbidities and use of antiplatelet/coagulation/NSAID have not been studied as a risk factor for small-bowel DL. Gastric DL studies have reported the prevalence of cardiovascular disease, diabetes, or chronic renal disease as high as $90 \%$ in patients found to have bleeding gastric DL [28]. Likewise the use of medications affecting coagulation has ranged from $28 \%$ to $51 \%$ of cases identified as gastric DL [ 16 , $28,36,39]$. Whether our high incidence of cardiac comorbidities occurred by chance, and whether the NSAID/antiplatelet use is related to an elderly population at risk for cardiac comorbidities/ arthritis remains to be determined with larger studies.

Limitations of our experience include the small cohort of patients diagnosed with DL and the retrospective study design. However, our experience adds to the very limited data on small-bowel DL found in the literature, and is the first US reported experience with an extended follow-up. We also have reported a more descriptive patient profile, and have demonstrated that SBE has been an effective treatment modality in patients found to have DL ( $100 \%$ success) in addition to reviewing the current literature on this topic.

\section{Conclusion \\ $\nabla$}

Misidentified, intermittent non-bleeding DL, or those not reachable with BAE may lead to an underdiagnoses and may explain at least a portion of idiopathic cases of OGIB. Therefore, we recommend an early aggressive approach with BAE after initial negative colonoscopy/EGD, or in cases where a high index of suspicion exists to ensure identification and treatment. The usefulness of repeating BAE after initial negative BAE should be determined based on clinical suspicion, previous diagnostic testing results, and the hemodynamic profile of each patient. In our U.S. experience, SBE offers a reasonable therapeutic approach to treat DL of the small bowel with a low rates of rebleeding, no adverse events, and no patient going on to require surgery.

\section{Competing interests: None}

Institutions

${ }^{1}$ University of South Florida Morsani College of Medicine, Department of Medicine, Tampa, Florida, United States

2 University of South Florida Morsani College of Medicine, Division of Digestive Diseases and Nutrition, Tampa, Florida, United States

3 University of South Florida Morsani College of Medicine, Department of Medicine, Division of Evidence Based Medicine and Outcomes Research, Tampa, Florida, United States

\section{References}

1 Shimizu S, Tada M, Kawai K. Development of a new insertion technique in push-type enteroscopy. Am J Gastroenterol 1987; 82: 844-847

2 Ell C, Remke S, May A et al. The first prospective controlled trial comparing wireless capsule endoscopy with push enteroscopy in chronic gastrointestinal bleeding. Endoscopy 2002; 34: 685-689

3 Monkemuller K, Bellutti M, Fry LC et al. Enteroscopy. Best Pract Res Clin Gastroenterol 2008; 22: 789-811

4 Takano N, Yamada A, Watabe $H$ et al. Single-balloon versus double-balloon endoscopy for achieving total enteroscopy: a randomized, controlled trial. Gastrointest Endosc 2011; 73: 734-739

5 Domagk D, Mensink P, Aktas $H$ et al. Single- vs. double-balloon enteroscopy in small-bowel diagnostics: a randomized multicenter trial. Endoscopy 2011; 43: $472-476$

6 May A, Farber M, Aschmoneit I et al. Prospective multicenter trial comparing push-and-pull enteroscopy with the single- and double-balloon techniques in patients with small-bowel disorders. Am J Gastroenterol 2010; 105: 575 - 581

7 Gallard T. Aneurysmes miliares de l'estomac, donnant lieu à des hématémèses mortelles [French]. Bull Soc Med Hôp Paris 1884; 1: 84-91

8 Stark ME, Gostout CJ, Balm RK. Clinical features and endoscopic management of Dieulafoy's disease. Gastrointest Endosc 1992; 38: 545 550

9 Matuchansky C, Babin P, Abadie JC et al. Jejunal bleeding from a solitary large submucosal artery. Report of two cases. Gastroenterology 1978; 75: $110-113$

10 Goldenberg SP, DeLuca VA Jr, Marignani P. Endoscopic treatment of Dieulafoy's lesion of the duodenum. Am J Gastroenterol 1990; 85: $452-454$

11 Dulic-Lakovic E, Dulic M, Hubner D et al. Bleeding Dieulafoy lesions of the small bowel: a systematic study on the epidemiology and efficacy of enteroscopic treatment. Gastrointest Endosc 2011; 74: 573-580

12 Fisher L, Lee Krinsky M, Anderson MA et al. The role of endoscopy in the management of obscure GI bleeding. Gastrointest Endosc 2010; 72: $471-479$

13 Hartmann D, Eickhoff A, Tamm $R$ et al. Balloon-assisted enteroscopy using a single-balloon technique. Endoscopy 2007; 39: $01 \mathrm{E} 276$

14 Bakka A, Rosseland AR. Massive gastric bleeding from exulceratio simplex (Dieulafoy). Acta Chir Scand 1986; 152: 285-288

15 Peitsch $W$, Lange $W$, Schauer A. [Dieulafoy's exulceratio simplex a rare but serious cause of acute upper gastrointestinal bleeding]. Dtsch Med Wochenschr 1987; 112: 1940-1942

16 Pointner R, Schwab G, Konigsrainer A et al. Endoscopic treatment of Dieulafoy's disease. Gastroenterology 1988; 94: 563-566

17 Case records of the Massachusetts General Hospital. Weekly clinicopathological exercises. Case 41-1991. A 76-year-old man with recurrent gastrointestinal bleeding. N Engl J Med 1991; 325: 1086-1096

18 Farrell DJ, Bennett MK. Dieulafoy's vascular malformation as a cause of large intestinal bleeding. J Clin Pathol 1992; 45: 363-366

19 Jaspersen D, Korner T, Schorr W et al. Extragastric Dieulafoy's disease as unusual source of intestinal bleeding. Esophageal visible vessel. Dig Dis Sci 1994; 39: $2558-2560$

20 Baettig B, Haecki W, Lammer F et al. Dieulafoy's disease: endoscopic treatment and follow up. Gut 1993; 34: 1418-1421

21 Parra-Blanco A, Takahashi H, Mendez Jerez PV et al. Endoscopic management of Dieulafoy lesions of the stomach: a case study of 26 patients. Endoscopy 1997; 29: $834-839$

22 Landaeta J, Paternina R. Efficacy of endoscopic treatment of Dieulafoy lesions of the small bowel. In: Proceedings from the Digestive Disease Week Annual Meeting; May 18-21, 2013: Abstract SA1665 2013

23 Chen TH, Chiu CT, Lin WP et al. Application of double-balloon enteroscopy in jejunal diverticular bleeding. World J Gastroenterol 2010; 16: $5616-5620$

24 Prachayakul V, Deesomsak M, Aswakul P et al. The utility of single-balloon enteroscopy for the diagnosis and management of small bowel 
disorders according to their clinical manifestations: a retrospective review. BMC Gastroenterol 2013; 13: 103

25 Paliwal M, Madan K et al. Small bowel Dieulafoy's: diagnosis, management and coutcome. J Gastroenterol Hepatol 2011; 26: 249 Abstract 210

26 Chung CS, Huang CT, Wang HP et al. Single-balloon enteroscopy for the management of a bleeding Dieulafoy lesion in the jejunal diverticulum. J Formos Med Assoc 2011; 110: 724-725

27 Ciobanu L, Pascu O, Diaconu B et al. (2013) Bleeding Dieulafoy's-like lesions of the gut identified by capsule endoscopy. World J Gastroenterol 2013; 19: 4823-4826

28 Norton ID, Petersen BT, Sorbi D et al. Management and long-term prognosis of Dieulafoy lesion. Gastrointest Endosc 1999; 50: 762 - 767

29 Chung IK, Kim EJ, Lee MS et al. Bleeding Dieulafoy's lesions and the choice of endoscopic method: comparing the hemostatic efficacy of mechanical and injection methods. Gastrointest Endosc 2000; 52: $721-724$

30 Park CH, Sohn YH, Lee WS et al. The usefulness of endoscopic hemoclipping for bleeding Dieulafoy lesions. Endoscopy 2003; 35: 388 - 392

31 Alis H, Oner OZ, Kalayci MU et al. (2009) Is endoscopic band ligation superior to injection therapy for Dieulafoy lesion? Surg Endosc 2009; 23: $1465-1469$
32 Hwang JH, Fisher DA, Ben-Menachem T et al. The role of endoscopy in the management of acute non-variceal upper GI bleeding. Gastrointest Endosc 2012; 75: 1132 - 1138

33 Katsinelos P, Paroutoglou G, Mimidis K et al. (2005) Endoscopic treatment and follow-up of gastrointestinal Dieulafoy's lesions. World J Gastroenterol 2005; 11: 6022-6026

34 Veldhuyzen van Zanten SJ, Bartelsman JF, Schipper ME et al. Recurrent massive haematemesis from Dieulafoy vascular malformations-a review of 101 cases. Gut 1986; 27: 213-222

35 Mumtaz R, Shaukat M, Ramirez FC. Outcomes of endoscopic treatment of gastroduodenal Dieulafoy's lesion with rubber band ligation and thermal/injection therapy. J Clin Gastroenterol 2003; 36: 310-314

36 Juler GL, Labitzke HG, Lamb R et al. The pathogenesis of Dieulafoy's gastric erosion. Am J Gastroenterol 1984; 79: 195-200

37 Skok P. Endoscopic hemostasis in exulceratio simplex-Dieulafoy's disease hemorrhage: a review of 25 cases. Endoscopy 1998; 30: 590 - 594

38 Dy NM, Gostout CJ, Balm RK. Bleeding from the endoscopically-identified Dieulafoy lesion of the proximal small intestine and colon. Am J Gastroenterol 1995; 90: 108-111

39 Kasapidis P, Georgopoulos P, Delis V et al. Endoscopic management and long-term follow-up of Dieulafoy's lesions in the upper GI tract. Gastrointest Endosc 2002; 55: 527-531 